\title{
Evaluation of the health literacy levels of patients applying to Family Medicine outpatient clinics
}

\author{
ZERRIN GAMSIZKAN ${ }^{1, A, B, E, F}$, MEHMET ALI SUNGUR ${ }^{2, A, C-E}$ \\ ORCID ID: 0000-0001-8677-4004 \\ ORCID ID: 0000-0001-5380-0819
}

${ }^{1}$ Department of Family Medicine, Düzce University Medical School, Düzce, Turkey

${ }^{2}$ Department of Biostatistics and Medical Informatics, Düzce University Medical School, Düzce, Turkey

A - Study Design, B - Data Collection, C - Statistical Analysis, D - Data Interpretation, E - Manuscript Preparation, F - Literature Search, G - Funds Collection

Summary Background. Today, the concept of health literacy is used to determine the health needs of the population in parallel with ever-increasing health knowledge.

Objectives. The aim of the study is to evaluate the health literacy level of patients who apply to the Family Medicine preventive health services of Düzce University Hospital and to investigate the relevant factors that may be related to health literacy.

Material and methods. This study was a cross-sectional study carried out between October 2018 and April 2019. The patients were evaluated utilizing the "Health Literacy Survey-European Union (HLS-EU)" scale. The study took place in Düzce Medical Faculty Hospital, Turkey.

Results. A total of 816 patients, $48.5 \%(n=396)$ of them male and $51.4 \%(n=420)$ female, were included in the study. The general health literacy levels of the patients were as follows: $30.6 \%(n=250)$ insufficient, $33.4 \%(n=272)$ limited, $28.9 \%(n=236)$ sufficient, $7.1 \%(n=58)$ excellent. According to all subdimensions and matrix averages of the scale used in the study, the mean score that patients received in understanding and applying health information in the disease prevention dimension $(8.45 \pm 2.30,8.10 \pm 2.38$, respectively) was found to be lower than health care $(11.20 \pm 2.72,11.63 \pm 3.01$, respectively).

Conclusions. The study results revealed a lower level of health literacy in terms of disease prevention rather than healthcare utilization. Initiatives to increase people's knowledge of disease prevention should be planned.

Key words: health literacy, health promotion, preventive medicine, primary health care.

Gamsızkan Z, Sungur MA. Evaluation of the health literacy levels of patients applying to Family Medicine outpatient clinics. Fam Med Prim Care Rev 2021; 23(2): 157-162, doi: https://doi.org/10.5114/fmpcr.2021.105907.

\section{Background}

An effective coordination of all stakeholders, including patients, healthcare workers, health institutions and health policy makers, is essential for the health service to function properly. In order to improve the health of individuals and society and to make the best use of the health system, the needs of all stakeholders should be known. For patients, one of these requirements is the need to access and evaluate health information. Authors on this subject say that patients have difficulty in understanding and interpreting the information provided to them in a healthcare setting [1]. Although health literacy has many definitions in literature, if it is defined simply, it can be said that it is the capacity to access and understand the necessary information while making decisions about the health of the person [2]. Health literacy is a concept first described by Simonds in 1974 [3]. It then started to be redefined and discussed in the 1990s. The concept of health literacy continues to be discussed with more and more parameters as content. Health literacy is not a technical issue that requires only reading and some cognitive skills, it includes combining combined readings, listening and understanding, as well as analytical and decision-making skills. Individuals demanding health services have different roles, such as gathering information about health problems, knowing their responsibilities and rights and making health-related decisions [4].

Although it seems easy to access information with all the possibilities in our current age, it may not always be possible to correctly understand, interpret and apply the information obtained. In his work on parents who could not provide information about the health of their children, because they do not understand the information requested, Scotten emphasizes that one in every ten adults in America has difficulty in using daily health information routinely provided by healthcare providers [5]. Strengthening the knowledge of these patients and increasing their participation in health decision-making processes is one of the efforts of the World Health Organization to increase the quality of health services [6]. Low levels of health literacy are associated with an inefficient use of preventive healthcare services, an increased number of hospital visits, increased healthcare costs and deterioration of public health [7]. In line with these requirements, as in all other fields, in order to live a better life and maximize the health literacy of individuals, various health education projects are being developed under the title of adult education and health literacy education [8].

Considering the areas where health literacy is related to many parameters, it is important to determine the health literacy level of the individuals and the society in order to follow the health-related outcomes. As a result of this need, many health literacy scales have been developed, and many studies have been conducted since the issue was discussed $[9,10]$. In this context, it is important to use health literacy research results in terms of health promotion.

The family medicine discipline, whose most important task is preventive health services, emphasizes that patients should be well read concerning health literacy. It is stated that visual tools and concrete information packages should be provided 
for patients to understand and use health information correctly [11]. In this context, we thought that we could direct our health promotion resources by determining the health literacy of patients who applied to Family Medicine outpatient clinics. An examination of the characteristic features and health literacy patterns of patients when accessing information about their own health and understanding and using the given information can provide a different perspective on the subject. Determining the level of health literacy of the society at all levels of health care, identifying in which areas there are problems and evaluating all the results together will help to guide public health policies. The aim of this study was to measure the health literacy level of patients who came to the hospital with a demand for preventive health care services and to investigate the factors that may be related to health literacy.

\section{Material and methods}

\section{Study design}

This is cross-sectional study and includes a sample of patients admitted to the Family Medicine outpatient clinics of Düzce University Hospital between October 2018 and April 2019. Data was collected from patients over 18 years old applying to periodic examination and preventive health services at the Family Medicine outpatient clinics. Exclusion criteria was determined as: illiteracy, being mentally ill and being health workers. The minimum sample size required to analyze the $14.5 \%$ excellent health literacy rate reported in the original study, in which the validity and reliability of the scale used in this study in Turkish, was made [12] with a type I error rate of 0.05 at a 0.95 confidence level, and a deviation of 0.025 was calculated as 762 . After determining the sample, the informed consent of the patients included in the study was obtained by the researcher in the waiting room. The participants were asked to complete the European health literacy survey (HLS-EU), as well as a questionnaire about sociodemographic characteristics, number of hospital visits in the last year, general health status assessment, number of books read per year and the presence of chronic diseases.

\section{Setting}

The study was carried out in Düzce University Family Medicine periodic examination clinic. There are two polyclinics practicing within the scope of preventive health services belonging to the Department of Family Medicine in Düzce Medical Faculty Hospital. In these outpatient clinics, annual periodic examinations of patients are organized. Obesity, diabetes and cardiovascular disease risks are evaluated, and early cancer screening tests are performed. Healthy nutrition and life counseling services are provided to protect patients from chronic diseases.

\section{Participants}

The sample of our study consisted of patients receiving service from these polyclinics within the research period.

\section{Study size}

There were 1,830 patient enrollments in the mentioned polyclinics during the study period. The response rate was 44.5\%. Data from the 816 participants (396 male, 420 female) who completed the questionnaire and scale were used.

\section{Data measurement}

The measuring tool used was the HLS-EU, which has been adapted to Turkish by Abacıgil et al. [12]. The scale was developed by the HLS-EU Consortium. It is a self-reporting scale de- veloped to evaluate health literacy in literate people over the age of 15 . The scale consists of three health dimensions and four cognitive subdimensions in the form of access to information, understanding, evaluation and application. The three dimensions related to health are: health care, disease prevention and health promotion. Each of the items is graded as: 1 - very difficult; 2 - difficult; 3 - easy; and 4 - very easy. The total score that can be obtained from the scale is between 47-188. The $\mathrm{HL}$ indices were standardized between the values of 0 and 50 using the "(mean-1).(50/3)" formula, where the mean was the arithmetical mean of responses to all 47 items in the questionnaire for each person. In this way, an index value between 0 and 50 was obtained, with 0 representing the lowest $\mathrm{HL}$ and 50 representing the highest. Health literacy levels are as follows: < 26- "inadequate"; 26-33 - "problematic"; 34-42 - "adequate"; and 43-50 - "excellent" [13]

\section{Definition of variables}

Age, gender, education level, general health status, presence of chronic diseases, number of hospital visits in last year and number of books read annually were questioned as sociodemographic characteristics as well as health literacy level by HLE-EU questionnaire. There were 816 participants (396 male, 420 female) with a mean age of $40.26 \pm 14.69$ (range, 18-82) years. Median number of hospital visits in last year was 2 (range, 0-15) and median number of books read was 0 (range, 0-20).

\section{Statistical methods}

Statistical analyses were conducted using SPSS (Statistical Package for the Social Sciences) (v. 22; Chicago, IL, USA). Normality assumption was examined by the Kolomogorov-Simirnov test. For independent samples, the $t$-Test and one-way ANOVA (ANalysis Of VAriance) or Mann-Whitney $U$ test and Kruskal-Wallis test were used to analyze numerical data, according to normality assumption and number of groups compared. Descriptive statistics were given as mean \pm standard deviation or median (minimum-maximum), as appropriate. Categorical data was analyzed with the Pearson chi-squared test and summarized as a frequency and percentage. Correlation analysis between continuous variables was investigated with the Pearson or Spearman correlation analysis according to normality assumption. Multiple regression analysis was done to evaluate the effect of variables on health literacy concerning data that was found to be significant in univariate analyses. The statistical significance level was considered as $p<0.05$.

\section{Ethical consideration}

Appropriate permission for the study was obtained from the Committee of Ethics of Düzce University (approval no: 2018/193). A consent form was received from all participants.

\section{Results}

A total of 816 patients, $48.5 \%(n=396)$ of them being male, were included in the study. In the study, there was no significant difference between health literacy levels according to gender ( $p=0.320, p=0.528, p=0.169$ and $p=0.433$, respectively). As the age of the patients (mean age: $40.26 \pm 14.69$ ) increased, overall health literacy and index scores in the three dimensions were significantly lower (all $p$-values were $<0.001$ ).

When the education levels of the patients are divided into four groups (literate, primary school, high school and university graduates): $6.4 \%$ ( $n=53$ ) of the patients were literate, $35.5 \%$ $(n=290)$ were primary school graduates, $26.8 \%(n=219)$ were high school graduates, and $31.1 \%(n=254)$ were university graduates. It was found that general health literacy increased as the education level of the patients increased $(p<0.001)$. In 


\begin{tabular}{|c|c|c|c|c|}
\hline & $\begin{array}{l}\text { General health } \\
\text { literacy }\end{array}$ & Health care & Disease prevention & Health promotion \\
\hline $\begin{array}{l}\text { Gender } \\
\quad \text { male }(n=396) \\
\text { female }(n=420)\end{array}$ & $\begin{array}{l}p=0.320 \\
29.05 \pm 9.12 \\
29.69 \pm 9.41\end{array}$ & $\begin{array}{l}p=0.528 \\
29.83 \pm 9.55 \\
30.27 \pm 10.27\end{array}$ & $\begin{array}{l}p=0.169 \\
28.30 \pm 10.06 \\
29.27 \pm 10.08\end{array}$ & $\begin{array}{l}p=0.433 \\
28.97 \pm 10.08 \\
29.52 \pm 9.93\end{array}$ \\
\hline Age & $p<0.001$ & $p<0.001$ & $p<0.001$ & $p<0.001$ \\
\hline $\begin{array}{l}\text { Education } \\
\text { literate }(n=53) \\
\text { primary school }(n=290) \\
\text { high school }(n=219) \\
\text { university }(n=254)\end{array}$ & $\begin{array}{l}p<0.001 \\
20.69 \pm 8.10^{\mathrm{a}} \\
25.32 \pm 8.92^{\mathrm{b}} \\
30.64 \pm 8.32^{\mathrm{c}} \\
34.74 \pm 6.94^{\mathrm{d}}\end{array}$ & $\begin{array}{l}p<0.001 \\
21.76 \pm 9.01^{\mathrm{a}} \\
25.78 \pm 10.02^{\mathrm{b}} \\
31.27 \pm 8.75^{\mathrm{c}} \\
35.62 \pm 7.21^{\mathrm{d}} \\
\end{array}$ & $\begin{array}{l}p<0.001 \\
19.98 \pm 8.78^{\mathrm{a}} \\
24.87 \pm 9.59^{\mathrm{b}} \\
30.08 \pm 9.52^{\mathrm{c}} \\
34.02 \pm 8.08^{\mathrm{d}}\end{array}$ & $\begin{array}{l}p<0.001 \\
20.30 \pm 8.68^{\mathrm{a}} \\
25.28 \pm 9.55^{\mathrm{b}} \\
30.55 \pm 9.02^{\mathrm{c}} \\
34.53 \pm 8.25^{\mathrm{d}}\end{array}$ \\
\hline $\begin{array}{l}\text { Job } \\
\text { housewife }(n=163) \\
\text { worker }(n=189) \\
\text { retired }(n=71) \\
\text { student }(n=124) \\
\text { officer }(n=160) \\
\text { self-employment }(n=109)\end{array}$ & $\begin{array}{l}p<0.001 \\
26.66 \pm 9.37^{\mathrm{a}} \\
25.46 \pm 9.18^{\mathrm{a}} \\
24.86 \pm 9.23^{\mathrm{a}} \\
33.42 \pm 7.04^{\mathrm{b}} \\
35.40 \pm 6.53^{\mathrm{b}} \\
29.75 \pm 8.48^{\mathrm{c}} \\
\end{array}$ & $\begin{array}{l}p<0.001 \\
27.51 \pm 10.65^{\mathrm{ab}} \\
25.78 \pm 9.97^{\mathrm{a}} \\
25.38 \pm 10.56^{\mathrm{a}} \\
34.26 \pm 6.75^{\mathrm{c}} \\
36.12 \pm 7.03^{\mathrm{c}} \\
30.62 \pm 8.45^{\mathrm{b}} \\
\end{array}$ & $\begin{array}{l}p<0.001 \\
26.09 \pm 10.17^{\mathrm{ab}} \\
24.87 \pm 9.91^{\mathrm{a}} \\
24.65 \pm 9.30^{\mathrm{a}} \\
32.08 \pm 8.43^{\mathrm{cd}} \\
35.27 \pm 7.84^{\mathrm{d}} \\
29.12 \pm 9.43^{\mathrm{bc}} \\
\end{array}$ & $\begin{array}{l}p<0.001 \\
26.34 \pm 9.79^{\mathrm{ab}} \\
25.70 \pm 9.67^{\mathrm{a}} \\
24.55 \pm 10.27^{\mathrm{a}} \\
33.84 \pm 8.66^{\mathrm{c}} \\
34.81 \pm 7.48^{\mathrm{c}} \\
29.46 \pm 9.64^{\mathrm{b}} \\
\end{array}$ \\
\hline $\begin{array}{l}\text { General health status } \\
\text { good }(n=374) \\
\text { moderate }(n=355) \\
\text { bad }(n=87)\end{array}$ & $\begin{array}{l}p<0.001 \\
31.67 \pm 9.30^{\mathrm{a}} \\
28.27 \pm 8.58^{\mathrm{b}} \\
24.04 \pm 8.93^{\mathrm{c}} \\
\end{array}$ & $\begin{array}{l}p<0.001 \\
32.29 \pm 9.92^{\mathrm{a}} \\
29.14 \pm 9.14^{\mathrm{b}} \\
24.14 \pm 10.10^{\mathrm{c}} \\
\end{array}$ & $\begin{array}{l}p<0.001 \\
31.21 \pm 9.99^{a} \\
27.44 \pm 9.69^{b} \\
23.97 \pm 9.30^{c} \\
\end{array}$ & $\begin{array}{l}p<0.001 \\
31.49 \pm 9.88^{\mathrm{a}} \\
28.18 \pm 9.58^{\mathrm{b}} \\
23.99 \pm 9.60^{\mathrm{c}}\end{array}$ \\
\hline Hospital visits in the last year & $p<0.001$ & $p<0.001$ & $p<0.001$ & $p<0.001$ \\
\hline $\begin{array}{l}\text { Presence of chronic diseases } \\
\text { none }(n=611) \\
\text { one chronic disease }(n=125) \\
\text { more than one chronic disease }(n=80)\end{array}$ & $\begin{array}{l}p<0.001 \\
31.38 \pm 8.47^{\mathrm{a}} \\
23.69 \pm 9.36^{\mathrm{b}} \\
22.95 \pm 8.45^{\mathrm{b}}\end{array}$ & $\begin{array}{l}p<0.001 \\
32.16 \pm 8.97^{a} \\
24.09 \pm 10.23^{b} \\
23.31 \pm 9.67^{b}\end{array}$ & $\begin{array}{l}p<0.001 \\
30.69 \pm 9.41^{\mathrm{a}} \\
23.67 \pm 10.46^{\mathrm{b}} \\
22.38 \pm 8.98^{\mathrm{b}}\end{array}$ & $\begin{array}{l}p<0.001 \\
31.26 \pm 9.33^{\mathrm{a}} \\
23.32 \pm 9.96^{\mathrm{b}} \\
23.14 \pm 8.90^{\mathrm{b}}\end{array}$ \\
\hline Number of books read per year & $p<0.001$ & $p<0.001$ & $p<0.001$ & $p<0.001$ \\
\hline
\end{tabular}

* Descriptive statistics of health literacy in groups were given as mean \pm standard deviation (SD). Correlation between health literacy and numerical variables (age, hospital visits in the last year and number of books read per year) were given as correlation coefficient ( $r$ ).

$a, b, c, d$ - different superscript letters denote the significant difference between groups according to the post hoc test results.

\begin{tabular}{|l|l|l|l|l|l|}
\hline Table 2. Health literacy scores and distribution of subgroups \\
\hline \multirow{2}{*}{} & Cronbach's $\alpha$ & \multicolumn{4}{|l|}{ Health literacy levels $(n, \%)$} \\
\cline { 3 - 6 } & & Insufficient & Limited & Sufficient & Excellent \\
\hline General health literacy & 0.970 & $250(30.6)$ & $272(33.3)$ & $236(28.9)$ & $58(7.1)$ \\
\hline Health care & 0.927 & $245(30.0)$ & $222(27.2)$ & $269(33.0)$ & $80(9.8)$ \\
\hline Disease prevention & 0.919 & $279(34.2)$ & $231(28.3)$ & $227(27.8)$ & $79(9.7)$ \\
\hline Health promotion & 0.936 & $281(34.4)$ & $223(27.3)$ & $223(27.3)$ & $89(10.9)$ \\
\hline
\end{tabular}

addition, health literacy levels in the health care $(p<0.001)$, disease prevention $(p<0.001)$ and health promotion $(p<0.001)$ dimensions were found to be significantly higher as the education level increased.

According to the assessment of general health status, levels of general health literacy from the scale we used significantly increased when the patients evaluated their general health status from "bad" to "good" ( $p$-values for all dimensions were $<0.001$ ). It was found that health literacy levels decreased significantly as the number of hospital visits increased within a year ( $p$-values for all dimensions were $<0.001$ ). Health literacy levels were found to be significantly higher as the number of books read by patients increased during the year (all $p$-values were $<0.001$ ). When the relationship between the presence of chronic disease and health literacy is examined, it was found that the health literacy levels of patients without any chronic diseases were significantly higher than those with one or more chronic diseases (all $p$-values were $<0.001$ ) (Table 1).

The general health literacy levels of the patients participating in the study were as follows: insufficient health literacy level $(30.6 \% ; n=250)$; limited health literacy level $(33.4 \% ; n=272)$; sufficient health literacy level $(28.9 \% ; n=236)$; and excellent health literacy level $(7.1 \% ; n=58)$. The internal consistency val- ues of the scale scores we determined in the study were: general health literature, health care, disease prevention and health promotion (Cronbach's alpha values were: 0.970, 0.927, 0.919 and 0.936 , respectively) (Table 2).

According to the comparison of demographic characteristics, health history of patients and the health literacy index, there were no significant differences in gender literacy levels in the adequate, inadequate, limited and excellent index groups ( $p=0.609$ ), but significant differences were observed according to age $(p<0.001)$, education $(p<0.001)$, general health status assessment $(p<0.001)$, number of annual hospital visits $(p<0.001)$, presence of chronic diseases $(p<0.001)$ and number of books read annually $(p<0.001)$ (Table 3 ).

When the demographic characteristics and health history of the patients were evaluated by multiple regression analysis of all subdimensions of the health literacy scale, in terms of accessing and understanding of the health service, education (both $p<0.001$ ), annual hospital visits (both $p<0.001$ ) and annual number of books read (both $p<0.001$ ) were found to be significantly different. In addition, in terms of appraising and applying health care, only education (both $p<0.001$ ) and number of books read per year (both $p<0.001$ ) were significantly related. In terms of understanding and appraising disease prevention, education (both $p<0.001$ ) and the number of books 
read annually (both $p<0.001$ ) showed significant differences. In terms of health promotion, access to information and understanding of the information differed significantly with the number of books read annually (both $p<0.001$ ) and education (both $p<0.001$ ), whereas the appraising and applying of knowledge was significantly different with education (both $p<0.001$ ), the number of books read annually (both $p<0.001$ ) and hospital visits (both $p<0.001$ ) (Table 4).

\begin{tabular}{|c|c|c|c|c|c|}
\hline & $\begin{array}{l}\text { Insufficient } \\
(n=250)\end{array}$ & $\begin{array}{l}\text { Limited } \\
(n=272)\end{array}$ & $\begin{array}{l}\text { Sufficient } \\
(n=236)\end{array}$ & $\begin{array}{l}\text { Excellent } \\
(n=58)\end{array}$ & $p$ \\
\hline $\begin{array}{l}\text { Gender } \\
\quad \text { male }(n=396) \\
\text { female }(n=420)\end{array}$ & $\begin{array}{l}127(32.1) \\
123(29.3) \\
\end{array}$ & $\begin{array}{l}133(33.6) \\
139(33.1) \\
\end{array}$ & $\begin{array}{l}112(28.3) \\
124(29.5) \\
\end{array}$ & $\begin{array}{l}24(6.1) \\
34(8.1) \\
\end{array}$ & 0.609 \\
\hline Age & $46.53 \pm 14.76^{\mathrm{a}}$ & $39.72 \pm 14.68^{b}$ & $35.34 \pm 13.21^{\mathrm{c}}$ & $35.84 \pm 9.99^{c}$ & $<0.001$ \\
\hline $\begin{array}{l}\text { Education } \\
\text { literate }(n=53) \\
\text { primary school }(n=290) \\
\text { high school }(n=219) \\
\text { university }(n=254)\end{array}$ & $\begin{array}{l}38(71.7)^{\mathrm{a}} \\
141(48.6)^{\mathrm{b}} \\
46(21.0)^{\mathrm{c}} \\
25(9.8)^{\mathrm{d}}\end{array}$ & $\begin{array}{l}12(22.6)^{\mathrm{a}} \\
94(32.4)^{\mathrm{a}} \\
85(38.8)^{\mathrm{a}} \\
81(31.9)^{\mathrm{a}}\end{array}$ & $\begin{array}{l}3(5.7)^{\mathrm{a}} \\
45(15.5)^{\mathrm{a}} \\
77(35.2)^{\mathrm{b}} \\
111(43.7)^{\mathrm{b}}\end{array}$ & $\begin{array}{l}0(0.0)^{\mathrm{a}} \\
10(3.4)^{\mathrm{a}} \\
11(5.0)^{\mathrm{a}} \\
37(14.6)^{\mathrm{b}}\end{array}$ & $<0.001$ \\
\hline $\begin{array}{l}\text { General health status } \\
\text { good }(n=374) \\
\text { moderate }(n=355) \\
\text { bad }(n=87)\end{array}$ & $\begin{array}{l}81(21.7)^{\mathrm{a}} \\
122(34.4)^{\mathrm{b}} \\
47(54.0)^{\mathrm{c}}\end{array}$ & $\begin{array}{l}117(31.3)^{\mathrm{a}} \\
127(35.8)^{\mathrm{a}} \\
28(32.2)^{\mathrm{a}}\end{array}$ & $\begin{array}{l}133(35.6)^{\mathrm{a}} \\
93(26.2)^{\mathrm{b}} \\
10(11.5)^{\mathrm{c}}\end{array}$ & $\begin{array}{l}43(11.5)^{\mathrm{a}} \\
13(3.7)^{\mathrm{b}} \\
2(2.3)^{\mathrm{b}}\end{array}$ & $<0.001$ \\
\hline Hospital visits in the last year & $4.54 \pm 2.39$ & $3.26 \pm 2.00$ & $2.68 \pm 1.53$ & $2.29 \pm 1.17$ & $<0.001$ \\
\hline $\begin{array}{l}\text { Presence of chronic disease } \\
\text { none }(n=611) \\
\text { one chronic disease }(n=125) \\
\text { more than one chronic disease }(n=80)\end{array}$ & $\begin{array}{l}131(21.4)^{\mathrm{a}} \\
71(56.8)^{\mathrm{b}} \\
48(60.0)^{\mathrm{b}} \\
\end{array}$ & $\begin{array}{l}217(35.5)^{\mathrm{a}} \\
31(24.8)^{\mathrm{a}} \\
24(30.0)^{\mathrm{a}}\end{array}$ & $\begin{array}{l}208(34.0)^{\mathrm{a}} \\
20(16.0)^{\mathrm{b}} \\
8(10.0)^{\mathrm{b}}\end{array}$ & $\begin{array}{l}55(9.0)^{a} \\
3(2.4)^{b} \\
0(0.0)^{b}\end{array}$ & $<0.001$ \\
\hline Number of books read per year & $0.22 \pm 1.37$ & $0.70 \pm 2.14$ & $2.37 \pm 3.73$ & $5.76 \pm 4.72$ & $<0.001$ \\
\hline
\end{tabular}

* Descriptive statistics were given as mean \pm standard deviation (SD) or median (minimum-maximum), as appropriate. Categorical variables were summarized as frequency (percent).

$a, b, c$ - different superscript letters denote the significant difference between groups according to the post hoc test results.

\begin{tabular}{|c|c|c|c|c|c|c|c|c|}
\hline & \multicolumn{2}{|c|}{ Accessing } & \multicolumn{2}{|c|}{ Understanding } & \multicolumn{2}{|c|}{ Appraising } & \multicolumn{2}{|c|}{ Applying } \\
\hline & $B$ & $p$ & $B$ & $p$ & $B$ & $p$ & $B$ & $p$ \\
\hline $\begin{array}{l}\text { Health care } \\
\text { age } \\
\text { education } \\
\text { general health status } \\
\text { hospital visits } \\
\text { chronic disease } \\
\text { number of books read }\end{array}$ & $\begin{array}{l}-0.055 \\
2.571 \\
-0.393 \\
-1.003 \\
-1.399 \\
0.830\end{array}$ & $\begin{array}{l}0.066 \\
<0.001 \\
0.534 \\
<0.001 \\
0.047 \\
<0.001 \\
\end{array}$ & $\begin{array}{l}-0.013 \\
2.743 \\
0.239 \\
-1.029 \\
-1.321 \\
0.638\end{array}$ & $\begin{array}{l}0.657 \\
<0.001 \\
0.705 \\
<0.001 \\
0.061 \\
<0.001\end{array}$ & $\begin{array}{l}0.050 \\
3.015 \\
0.416 \\
-0.824 \\
-1.467 \\
0.734\end{array}$ & $\begin{array}{l}0.133 \\
<0.001 \\
0.551 \\
0.001 \\
0.059 \\
<0.001 \\
\end{array}$ & $\begin{array}{l}-0.032 \\
3.264 \\
1.072 \\
-0.689 \\
-1.827 \\
0.624\end{array}$ & $\begin{array}{l}0.350 \\
<0.001 \\
0.135 \\
0.007 \\
0.022 \\
<0.001\end{array}$ \\
\hline $\begin{array}{l}\text { Disease prevention } \\
\text { age } \\
\text { education } \\
\text { general health status } \\
\text { hospital visits } \\
\text { chronic disease } \\
\text { number of books read }\end{array}$ & $\begin{array}{l}-0.026 \\
3.299 \\
-0.357 \\
-0.562 \\
-0.936 \\
0.682\end{array}$ & $\begin{array}{l}0.436 \\
<0.001 \\
0.603 \\
0.022 \\
0.221 \\
<0.001\end{array}$ & $\begin{array}{l}-0.039 \\
2.680 \\
0.963 \\
-0.946 \\
-1.294 \\
0.630\end{array}$ & $\begin{array}{l}0.276 \\
<0.001 \\
0.194 \\
<0.001 \\
0.117 \\
<0.001\end{array}$ & $\begin{array}{l}0.035 \\
2.255 \\
0.283 \\
-0.939 \\
-1.907 \\
0.843\end{array}$ & $\begin{array}{l}0.257 \\
<0.001 \\
0.665 \\
<0.001 \\
0.009 \\
<0.001\end{array}$ & $\begin{array}{l}0.050 \\
3.644 \\
-0.547 \\
-0.456 \\
-1.288 \\
0.916\end{array}$ & $\begin{array}{l}0.169 \\
<0.001 \\
0.471 \\
0.091 \\
0.127 \\
<0.001\end{array}$ \\
\hline $\begin{array}{l}\text { Health promotion } \\
\text { age } \\
\text { education } \\
\text { general health status } \\
\text { hospital visits } \\
\text { chronic disease } \\
\text { number of books read }\end{array}$ & $\begin{array}{l}-0.024 \\
3.093 \\
-0.170 \\
-0.599 \\
-1.471 \\
0.885\end{array}$ & $\begin{array}{l}0.443 \\
<0.001 \\
0.792 \\
0.009 \\
0.041 \\
<0.001\end{array}$ & $\begin{array}{l}0.001 \\
2.758 \\
0.199 \\
-0.701 \\
-2.103 \\
0.706\end{array}$ & $\begin{array}{l}0.988 \\
<0.001 \\
0.765 \\
0.003 \\
0.005 \\
<0.001\end{array}$ & $\begin{array}{l}0.008 \\
3.137 \\
0.775 \\
-0.951 \\
-0.861 \\
0.734\end{array}$ & $\begin{array}{l}0.808 \\
<0.001 \\
0.250 \\
<0.001 \\
0.251 \\
<0.001\end{array}$ & $\begin{array}{l}0.001 \\
2.267 \\
0.757 \\
-0.955 \\
-1.204 \\
0.882\end{array}$ & $\begin{array}{l}0.983 \\
<0.001 \\
0.257 \\
<0.001 \\
0.106 \\
<0.001\end{array}$ \\
\hline
\end{tabular}

B- regression coefficient.

\begin{tabular}{|l|l|l|l|}
\hline Table 5. Average values of all sub-dimensions and matrixes of health literacy levels \\
\hline & Health care & Disease prevention & Health promotion \\
\hline Accessing health information & $11.07 \pm 2.83$ & $11.04 \pm 2.90$ & $13.81 \pm 3.52$ \\
\hline Understanding health information & $11.20 \pm 2.72$ & $8.45 \pm 2.30$ & $11.06 \pm 2.82$ \\
\hline Appraising health information & $10.96 \pm 2.90$ & $13.32 \pm 3.46$ & $8.34 \pm 2.13$ \\
\hline Applying health information & $11.63 \pm 3.01$ & $8.10 \pm 2.38$ & $10.88 \pm 2.81$ \\
\hline
\end{tabular}


According to all subdimensions and matrix averages of the scale used in the study, the mean score that patients received in understanding and applying health information in the disease prevention dimension $(8.45 \pm 2.30,8.10 \pm 2.38$, respectively) was found to be lower than health care $(11.20 \pm 2.72,11.63$ \pm 3.01 , respectively). In the health promotion dimension, the mean score of the patients' health information assessment was also lower than other dimensions $(8.34 \pm 2.13)$ (Table 5).

\section{Discussion}

According to the results of the study, it has been shown that the general health literacy level of the patients was insufficient and limited in more than half of the patients. These results overlap with the limited health literacy of more than half of the adults in America [14]. Similar low health literacy levels draw attention not only in America but also in many European countries [15]. Another remarkable finding of this multi-center study, which includes eight countries in Europe, is that the limited health literacy level is as wide as $29 \%$ and $69 \%$. The fact that the results of only one continent are so different suggests how different the levels of health literacy in the world can be. That is why we think that every country should evaluate its health literacy levels in all patient groups.

In the study, the educational level of the patients and their annual reading rate varied significantly with health literacy. This suggests that the parameters used are determinant features in health literacy, which is supported in literature $[16,17]$. In the study, in terms of understanding and evaluating the disease prevention dimension, patients with higher education had significantly higher health literacy levels. It is thought that higher education will naturally increase the level of health literacy. In order to increase the competence of individuals to understand, evaluate and apply health information, it will be best to develop various health education models. The definition of health literacy is still an evolving concept, with Rudd [18] proposing a wider perspective that includes the development of the communication skills of healthcare professionals who guide and consult the patient. In order to improve health literacy, interventions such as creating regular and constantly updated health education modules, patient-oriented communication and information sessions, as well as developing written and visual materials, are recommended [19].

It is stated in many studies that individuals who perceiving themselves as unhealthy are associated with low health literacy [20]. In the study, it was also observed that there was a significant increase in general health literacy levels when patients evaluated their health status from "bad" to "good". However, when this was evaluated in the context of subdimensions according to regression analysis, the levels of perception of a patient's own health status are not determined by the level of health literacy.

According to the study results, health literacy levels did not show a significant difference according to gender, but as the age of the patients increased, health literacy levels were significantly lower. In a community-based study, similar to our results, it was stated that there was no significant difference between health literacy compared to gender, and the health literacy of young participants was found to be higher [21]. Today, the necessity of meeting the health-related needs specific to aging societies will become more talked about. It is emphasized that primary care physicians should transform health information systems, especially for middle-aged and elderly patients, in order for them to have easy access to health information [22].

Limited health literacy is associated with low levels of health, limited use of preventive health care, increased hospital visits and mortality rates, as well as low physical and mental health $[23,24]$. In our study, the health literacy levels of the patients with more hospital visits during the year were significantly lower. In our study, it was determined that some participants were insufficient in understanding and applying the information in terms of preventing the disease. It should be reminded that patients who cannot manage health problems may have lower health literacy. If we look at the subject from a physician's perspective, it is important to consider the level of health literacy in order to obtain effective results for treatment.

There were some limitations that we need to mention about our study. First, we needed to try to define health literacy, which should also be read in social terms, only with quantitative data, which means seeing people as numbers. The study could be enriched with focus group discussions to determine the implicit needs of individuals. The fact that our study is cross-sectional is the most important limitation of our study, which we started in order to search for a predictor for health literacy. Nevertheless, after all regression analyses, we think that the relational outcome of the results of our study between education and health literacy point to a target that should be focused on. Although increasing the educational level of society is a long-term activity, we can improve the health of the society by explaining the results and guiding those patients with a lower education level in reaching, evaluating and applying health information.

\section{Conclusions}

This study, albeit with some limitations, shows that the patients who applied to Family Medicine periodic examination polyclinics had low health literacy. The study results revealed a lower level of health literacy in terms of disease prevention rather than healthcare utilization. In this context, it should be ensured that the health needs of individuals are met effectively by reading the reflections of studies on health literacy, on a correct basis. In order to not be exposed to the negative consequences of low health literacy, interventions can be planned in terms of improving health in areas identified as inadequate in the study results.

Source of funding: This work was funded from the authors' own resources.

Conflicts of interest: The authors declare no conflicts of interest.

\section{References}

1. Nielsen-Bohlman LT, Panzer AM, Hamlin B, et al., eds. Health literacy: a prescription to end confusion. Washington, DC: National Academies Press. April 2004. Available from URL: http://www.nap.edu/catalog/10883.html/.

2. McCaffery KJ, Holmes-Rovner M, Smith SK, et al. Addressing health literacy in patient decision aids. BMC Med Inform Decis Mak 2013; 13: 10, doi: 10.1186/1472-6947-13-S2-S10.

3. Keleher H, Hagger V. Health literacy in primary health care. Aust J Prım Health 2007; 13: 24-30.

4. Sukys S, Cesnaitiene VJ, Ossowsky ZM. Is health education at university associated with students' health literacy? Evidence from crosssectional study applying HLS-EU-Q. Biomed Res Int 2017; 2017: 8516843, doi: 10.1155/2017/8516843.

5. Scotten M. Parental health literacy and its impact on patient care. Prim Care 2015; 42: 1-16.

6. World Health Organization. WHO global strategy on people-centred and integrated health services INTERIM report. 2015. Available from URL: https://www.who.int/servicedeliverysafety/areas/people-centred-care/global-strategy/en/.

7. Heide I van der, Rademakers J, Schipper M, et al. Health literacy of Dutch adults: a cross sectional survey. BMC Public Health 2013; 13: 179, doi: 10.1186/1471-2458-13-179. 
8. Hohn MD, Rivera L. The impact and outcomes of Integrating health literacy education into adult basic education programs in Boston. Health Lit Res Pract 2019; 3: 25-32.

9. Osborne RH, Batterham RW, Elsworth GR, et al. The grounded psychometric development and initial validation of the health literacy questionnaire (HLQ). BMC Public Health 2013; 13: 658, doi: 10.1186/1471-2458-13-658.

10. Wang J, Thombs BD, Schmid MR. The Swiss Health Literacy Survey: development and psychometric properties of a multidimensional instrument to assess competencies for health. Health Expect 2014; 17: 396-417.

11. Hersh L, Salzman B, Snyderman D. Health literacy in primary care practice. Am Fam Physician 2015; 92(2): 118-124.

12. Abacigil F, Harlak H, Okyay P, et al. Validity and reliability of the Turkish version of the European Health Literacy Survey Questionnaire. Health Promot Int 2019; 34: 658-667.

13. Sørensen K, Broucke S van den, Doyle G, et al. (HLS-EU) Consortium Health Literacy Project European. Health literacy and public health: a systematic review and integration of definitions and models. BMC Public Health 2012; 12: 80, doi: 10.1186/1471-2458-12-80.

14. Kutner M, Greenberg E, Jin Y, et al. The health literacy of America's adults: results from the 2003 National Assessment of Adult Literacy. 2006; U.S. Department of Education NCES 2006. Available from URL: https://nces.ed.gov/pubs2006/2006483.pdf.

15. Sørensen K, Pelikan JM, Röthlin F, et al. HLS-EU Consortium. Health literacy in Europe: comparative results of the European health literacy survey (HLS-EU). Eur J Public Health 2015; 25: 1053-1058.

16. Heide I van der, Uiters E, Sørensen K, et al. EPHORT consortium. Health literacy in Europe: the development and validation of health literacy prediction models. Eur J Public Health 2016; 26: 906-911.

17. Joveini H, Rohban A, Askarian P, et al. Health literacy and its associated demographic factors in 18-65-year-old, literate adults in Bardaskan, Iran. J Educ Health Promot 2019; 31; 8: 244.

18. Rudd RE. Health literacy: insights and issues. Stud Health Technol Inform 2017; 240: 60-78.

19. McCormack L, Thomas V, Lewis MA, et al. Improving low health literacy and patient engagement: a social ecological approach. Patient Educ Couns 2017; 100: 8-13.

20. Toci E, Burazeri G, Jerliu N, et al. Health literacy, self-perceived health and self-reported chronic morbidity among older people in Kosovo. Health Promot Int 2015; 30: 667-674.

21. Toçi E, Burazeri G, Myftiu S, et al. Health literacy in a population-based sample of adult men and women in a South Eastern European country. J Public Health (Oxf) 2016; 38: 6-13.

22. Susło R, Paplicki M, Dopierała K, et al. Fostering digital literacy in the elderly as a means to secure their health needs and human rights in the reality of the twenty-first century. Fam Med Prim Care Rev 2018; 20(3): 271-275.

23. Berkman ND, Sheridan SL, Donahue KE, et al. Low health literacy and health outcomes: an updated systematic review. Ann Intern Med 2011; 155: 97-107.

24. Schumacher JR, Hall AG, Davis TC, et al. Potentially preventable use of emergency services: the role of low health literacy. Med Care 2013; 51: 654-658.

Tables: 0

Figures: 0

References: 24

Received: 27.10 .2020

Reviewed: 19.11 .2020

Accepted: 31.12 .2020

Address for correspondence:

Zerrin Gamsizkan, MD, Assist. Prof.

Department of Family Medicine

Düzce University Medical School

Konuralp 81100 Düzce

Turkey

Tel.: +90 3805421390 (ext. 6513)

E-mail: zgamsizkan@yahoo.com 